\title{
ESTIMATION OF EMPLOYEE TURNOVER \\ WITH COMPETING RISKS MODELS
}

Wioletta Grzenda, Ph.D.

Warsaw School of Economics

Collegium of Economic Analysis

Institute of Statistics and Demography

Madalińskiego 6/8, 02-513 Warsaw, Poland

e-mail:wgrzend@sgh.waw.pl

Michał K. Buczyński, MSc

Independent analyst

Tukana 11a, 02-843 Warsaw, Poland

e-mail: michal.buczynski@gmail.com

Received 28 April 2015, Accepted 22 November 2015

\begin{abstract}
Employee turnover accompanies every business organization, regardless of the industry and size. Nowadays, many companies struggle with problems related to the lack of sufficient information about the nature of employee turnover processes. Therefore, comprehensive analysis of these processes is necessary. This article aims to examine the turnover of employees from a big manufacturing company using competing risks models with covariates and without covariates. This technique allows to incorporate the information about the type of employment contract termination. Moreover, Cox proportional hazard model enables the researcher to analyse simultaneously multiple factors that affect employment duration. One of the major observations is that employee remuneration level differentiates most strongly the risk of job resignation.
\end{abstract}

Keywords: employee turnover, enterprise, competing risks model, Cox model, partial likelihood estimation

JEL classification: C14, J63 


\section{Introduction}

Proper analysis of processes related to employee fluctuation is vital for both employee and employer. Uncontrolled and excessive turnover might entail enormous direct and indirect costs for company (Staw, 1980). Therefore, thorough examination of the employee turnover might point to different factors that cause increased turnover. As a result, negative consequences of this phenomenon might be mitigated. From the employee's point of view, the knowledge about individual employee's characteristics that give a competitive edge on the labour market is crucial. Equally importantly, the identification of the employees which are the most exposed to the risk of involuntary turnover may be of interest.

Employee coming and going is frequently called employee fluctuation. There is no unequivocal definition of the employee fluctuation in the literature. Staff fluctuation might be understood to include every situation when an employee leaves a company (Cascio, 2001). Sometimes, this definition is narrowed down to voluntary turnover, which is when an employee consciously decides to leave the company (Pocztowski, 2009). One might encounter much wider definitions, such as: employee turnover is a diametrical change, exchange or a major loss of the staff members (Cybulski, 2008). For the purpose of this paper, this notion will be defined as process of external turnover including, but not limited to dismissals from the analysed company. Employee turnover might be voluntary and involuntary (Cascio, 2001). Voluntary turnover i.e. turnover decided upon by employees entails huge costs for company and despite that fact it is frequently downplayed by employers (Sidor-Rządkowska, 2010). According to Cascio, employer should consider the following two aspects when the employee decides to leave the organisation: his or her productivity and the possibilities of replacement with another employee (Cascio, 2001). From the company's point of view, the presence of the turnover might be beneficial for an organisation if only the process is adequately executed and controlled. It gives the opportunity to terminate the employment contract with unproductive employees, which in the long-term may positively affect the productivity of other employees through e.g. eradication of potential conflicts between workers.

The basic measurement of employee turnover is called fluctuation ratio or turnover ratio. It is calculated as a ratio of the number of employees who have left the organisation to the average headcount for the specified period of time. Various modifications of this indicator are also commonly used. However, these indicators do not allow to identify factors that might have significant influence on the intensity of the turnover process. Other methods of measuring turnover, which are present in the literature, such as correlation analysis or linear regression 
(Cybulski, 2008) do not incorporate time as a variable of interest. Therefore, it is justified to make use of survival analysis models in order to conduct a thorough analysis of the turnover process. Survival models are frequently used in the analysis of employment processes, mainly unemployment issues (Drobnič, Frątczak, 2001; Grzenda, 2012). These models are capable of measuring the event rate as well as determinants that influence the turnover process. Proportional hazard model allows to measure simultaneously the impact of multiple variables on the process of interest. This model has been proposed by Cox (Cox, 1972; 1975). The application of Cox model in the analysis of turnover of nurses can be found in Somers' (Somers, 1996) publication.

Termination of job contract may be initiated by the employer or by an employee. More detailed classifications of employment contract terminations identify the following categories: resignation of the employee, dismissal by the employer, mutual agreement between employer and employee, retirement or disability living allowance (DLA), disciplinary dismissal, inability to work, employee death or expiry of fixed-term contract. Competing risks model (see among others: Heckman \& Honoré, 1989), which has been used in this paper, is capable of analysing different types of employment termination. Gregory-Smith, Thompson and Wright have applied duration analysis to examine the tenure and mode of exit of CEOs in the United Kingdom (Gregory-Smith et al., 2009). They have included three ways of contract termination: involuntary turnover, retirement and other. In this paper four modes of exits have been distinguished.

\section{Competing risks model}

In this study, competing risks model has been used to examine the predictors that influence employee turnover in the company. Competing risks models belong to the group of time-toevent models, which are used to estimate the time until the occurrence of a particular event (failure time) (Kalbfleisch, Prentice, 2012; Kleinbaum, Klein, 2012). The most commonly used survival analysis models have only one designated event of interest. In the cases, when more than one event is considered, competing risks models are applied. Early deliberations on competing risks models can be found in the work of Prentice, Kalbfleisch, Peterson, Flournoy, Farewell and Breslow (Prentice et al., 1978). More contemporary works focusing on competing risks models were authored by Allison (Allison, 2010) and Klein (Klein, 2010).

Let $D_{1}, D_{2}, \ldots, D_{K}$ represent different types of competing risks. Moreover, let $T$ be a random variable denoting the time until the occurrence of the first of the possible event types. Next, we denote by $J$ the type of the event and by $K$ the number of all possible event types, 
$j=1,2, \ldots, K$. The probability that the first of competitive events will occur before or at time $t$ is given by the following formula:

$$
F_{j}(t)=P\left(T_{j} \leq t\right), \quad j=1,2, \ldots, K
$$

Hazard function has a key role in survival models. Now, we will specify the hazard function for competing risks model i.e. type specific hazard:

$$
h_{j}(t)=\lim _{\Delta t \rightarrow 0} \frac{P(t<T<t+\Delta t, J=j \mid T \geq t)}{\Delta t}, \quad j=1,2, \ldots, K
$$

Then, the overall hazard function is given by the following formula:

$$
h(t)=\sum_{j=1}^{K} h_{j}(t)
$$

Type-specific survival function is defined as follows:

$$
S_{j}(t)=\exp \left\{-\int_{0}^{t} h_{j}(u) d u\right\}
$$

or equivalently

$$
S_{j}(t)=P\left(T_{j}>t\right)
$$

Survival function informs us that the event type $j$ will not occur before the time $t$.

Cox proportional hazard model allows to estimate the effects of variables on survival time (Cox, 1972; Cox, Oakes, 1984). The unquestionable advantage of this model is that the researcher does not have to make any assumptions about the shape of the hazard function. The Cox's proportional hazard model can be formulated as follows:

$$
h_{j}(t ; \mathbf{x})=h_{0 j}(t) \exp \left(\hat{\mathbf{a}}_{j} \mathbf{x}\right), \quad j=1,2, \ldots, K
$$

where:

$x-$ is a vector of covariates,

$\beta_{j}-$ is a vector of regression coefficients for $j^{\text {th }}$ event type,

$h_{j}(\mathrm{t} ; \mathrm{x})$ - denotes the hazard at time $t$ for $j^{\text {th }}$ event type,

$h_{0 j}(\mathrm{t}), h_{0 j}(\mathrm{t})>0-$ is a parametrically non-specified function of time called baseline hazard function for $j^{\text {th }}$ event type.

If $\beta_{j}$ and $h_{0 j}(\mathrm{t})$ are identical across all $j$, then the model reduces to the ordinary proportional Cox hazard model with a single event type. 
Partial likelihood estimation, which has been developed by Cox (Cox, 1975), is widely used to estimate Cox model.

Competing risks models are capable of comparing hazards for different types of events. The occurrence of one type of event means that the individual is no longer at risk of experiencing all the other event types. More information about the competing risks model can be found in the works of Heckmann (Heckman, Honoré, 1989), Lunn (Lunn, McNeil, 1995) and Pintilie (2006).

\section{Model estimation}

\subsection{Research scope}

The data, which were used in this analysis, describe the employment duration (survival times) of 4,289 present and former employees from a big manufacturing company. Dependent variable was defined as time in months of employment. Having in mind the main aim of this study as well as the availability of the data, the use of the following independent variables has been proposed: sex, employee group, employee type, remuneration, affiliation to the collective labour agreement, education and age.

The characteristics of nominal variables is included in Table 1. Age, measured in years, was the only continuous variable used in the study $(\min =19, \max =75)$.

Table 1. Description of nominal variables

\begin{tabular}{|c|c|c|c|c|}
\hline Variable & Label & Category & Category label & $\begin{array}{c}\text { Number } \\
\text { of observations }\end{array}$ \\
\hline 1 & 2 & 3 & 4 & 5 \\
\hline \multirow{6}{*}{ Group } & \multirow{6}{*}{ Employee group } & 1 & Line managers & 291 \\
\hline & & 2 & Administration and office staff & 230 \\
\hline & & 3 & Factory staff & 1,655 \\
\hline & & 4 & Specialists & 1,667 \\
\hline & & 5 & Sales force & 240 \\
\hline & & 6 & Top/Middle Management & 206 \\
\hline \multirow{2}{*}{ Type } & \multirow{2}{*}{ Employee type } & 0 & Blue collar & 1,693 \\
\hline & & 1 & White collar & 2,596 \\
\hline \multirow{2}{*}{ Sex } & \multirow{2}{*}{ Sex } & 1 & Women & 784 \\
\hline & & 0 & Men & 3,505 \\
\hline \multirow{2}{*}{ Agreement } & \multirow{2}{*}{$\begin{array}{l}\text { Affiliation to collective } \\
\text { labour agreement }\end{array}$} & 1 & affiliated & 3,309 \\
\hline & & 0 & Not affiliated & 980 \\
\hline \multirow{4}{*}{ Remun } & \multirow{4}{*}{ Remuneration } & 1 & 1st level & 917 \\
\hline & & 2 & 2nd level & 1,134 \\
\hline & & 3 & 3rd level & 1,203 \\
\hline & & 4 & 4th level & 1,035 \\
\hline
\end{tabular}




\begin{tabular}{|l|l|l|l|r|}
\hline \multicolumn{1}{|c|}{2} & 3 & \multicolumn{1}{|c|}{4} & \multicolumn{1}{c|}{5} \\
\hline \multirow{4}{*}{ Edu } & \multirow{4}{*}{ Education } & 1 & Primary education & 183 \\
\cline { 3 - 5 } & & 2 & Vocational training & 1,306 \\
\cline { 2 - 5 } & & 3 & Secondary education & 516 \\
\cline { 2 - 5 } & & 4 & Higher education & 2,284 \\
\hline
\end{tabular}

Source: own calculations.

Four types of job terminations have been singled out: 1 - resignation by employee $(5.53 \%), 2$-job termination by employer (1.35\%), 3 - mutual agreement between employer and employee (8.77\%). Residual observations including: retirement or disability living allowance, disciplinary dismissal, inability to work, expiry of contract resulting from employee death or fixed-term contract were put together and created 4th category called, other exits (13.73\%). The rest of the observations have been censored $(70.62 \%)$.

Prior to the estimation of competing risks model, the Cox model assumptions had been tested, without differentiating the type of the job termination. The outlier observations have been removed from the dataset and significance of variables has been analysed. Sex, remuneration, employee group, education and age turned out to be statistically significant and have been included in the final model. SAS software was used to carry out the estimation and verification of all the models.

\subsection{Competing risks model without covariates}

Contrary to single event models, competing risks models are capable of analysing time until the occurrence of competing events. Figure 1 presents survival functions of all four types of job terminations.

The highest values of survival function possess the exits initiated by the employer (type 1). Moreover, the function for most of the time is quite stable. Slightly lower values of survival function might be observed in the case of resignations from the job by the employee (type 2). This curve behaves similarly to the previous one. Next curve, which is located under curves for type 1 and 2 exits, shows the exits resulted in mutual agreement between employer and employee. The smallest survival function values might be observed for other exits (type 4). Curves for type 3 and 4 exits have a tendency to diverge faster from the remaining two curves. What is more, almost all curves in the first 100 months from the start of employment, excluding the curve for type 1 exits, follow similar pattern (see Figure 1). 


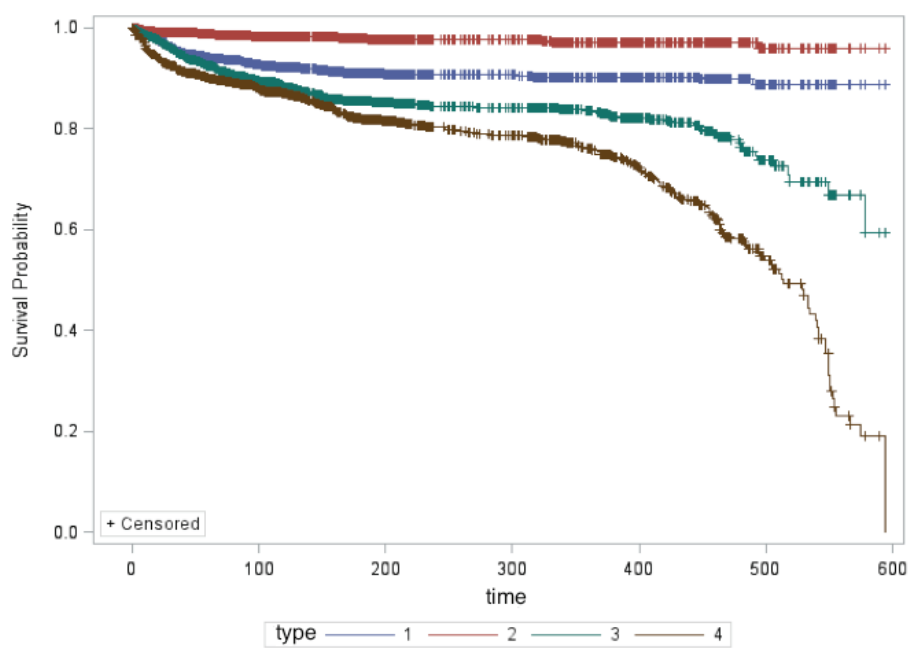

Figure 1. Survival plot for four types of job exits

Source: own calculations.

Parametric test proposed by Cox and Oakes (Cox, Oakes, 1984) has been applied to verify the proportional hazards hypothesis for each event type:

$$
h_{j}(t)=\omega_{j} h(t), \quad j=1,2,3,4
$$

where $\omega_{j}$ are the proportionality constants. To conduct the test, the following model has been estimated:

$$
\log h_{j}(t)=h_{0}(t)+h_{j}+\beta_{j} t, \quad j=1,2,3,4
$$

The test checked whether $\beta_{j}$ values are equal for all $j$. The outcomes of the test are presented in Table 2. We can see that the proportionality assumption should be rejected.

Table 2. Test of proportionality

\begin{tabular}{|l|c|c|c|c|r|c|}
\hline \multicolumn{1}{|c|}{ Parameter } & Event type & DF & Estimate & Standard error & Wald Chi-Square & p-value \\
\hline Intercept & 1 & 1 & -0.44700 & 0.095600 & 21.8474 & $<0.0001$ \\
\hline Intercept & 2 & 1 & -1.96470 & 0.166000 & 140.0260 & $<0.0001$ \\
\hline Intercept & 3 & 1 & -0.25060 & 0.081600 & 9.4263 & 0.0021 \\
\hline Time & 1 & 1 & -0.00618 & 0.001000 & 37.9951 & $<0.0001$ \\
\hline Time & 2 & 1 & -0.00410 & 0.001470 & 7.7971 & 0.0052 \\
\hline Time & 3 & 1 & -0.00193 & 0.000492 & 15.3176 & $<0.0001$ \\
\hline
\end{tabular}

Source: own calculations. 


\subsection{Competing risks model with covariates}

Competing risks models with covariates can analyse the effects of various variables on survival time until the occurrence of competitive destination events.

In order to examine the influence of selected characteristics on the risk of employee turnover, five Cox models for each event type have been estimated. In the first model, all event types have been treated as identical (see Table 3).

Table 3. Results of Cox model for all event types (Model 1)

\begin{tabular}{|l|c|r|r|r|r|c|}
\hline \multicolumn{1}{|c|}{ Parameter } & Event type & Estimate & Standard error & Chi-Square & $\mathrm{p}$-value & Hazard ratio \\
\hline Sex & 1 & -0.59922 & -0.59922 & 52.9717 & $<0.0001$ & 0.549 \\
\hline Remuneration & 3 & 0.38124 & 0.38124 & 15.0958 & 0.0001 & 1.464 \\
\hline Remuneration & 2 & 1.36493 & 1.36493 & 139.0111 & $<0.0001$ & 3.915 \\
\hline Remuneration & 1 & 3.11019 & 3.11019 & 525.0809 & $<0.0001$ & 22.425 \\
\hline Group & 1 & -0.46400 & -0.46400 & 5.7589 & 0.0164 & 0.629 \\
\hline Group & 2 & 0.29344 & 0.29344 & 2.2289 & 0.1355 & 1.341 \\
\hline Group & 3 & -1.64666 & -1.64666 & 76.6198 & $<0.0001$ & 0.193 \\
\hline Group & 4 & 0.11727 & 0.11727 & 0.5527 & 0.4572 & 1.124 \\
\hline Group & 5 & 0.25202 & 0.25202 & 1.8524 & 0.1735 & 1.287 \\
\hline Education & 3 & -0.35252 & -0.35252 & 11.2151 & 0.0008 & 0.703 \\
\hline Education & 2 & -0.58671 & -0.58671 & 34.7722 & $<0.0001$ & 0.556 \\
\hline Education & 1 & 0.42660 & 0.42660 & 11.5143 & 0.0007 & 1.532 \\
\hline Age & & -0.03835 & -0.03835 & 128.0647 & $<0.0001$ & 0.962 \\
\hline
\end{tabular}

Source: own calculations.

Model 1, with all event types, turned out to have all variables statistically significant at alpha equal to 0.05 , except for three levels of group variable. We learn that women had $45.1 \%$ higher risk of leaving the company compared to men. Employees in groups where remuneration was lower than in the highest group were exposed to the higher risk of turnover. Workers in the lowest salary group were the most vulnerable to the risk of leaving the company. Line managers had $37.1 \%$ lower risk of leaving the job, whereas factory staff had $80.7 \%$ smaller risk compared to the top and middle management group. Employees with secondary and vocational education had $29.7 \%$ and $44.4 \%$ lower risk of dismissal, respectively compared to the co-workers with higher education. Workers who possessed primary education had $53.2 \%$ higher risk of job contract termination compared to the reference group. Last but not least, one year increase in the age of employee led to $3.8 \%$ decrease in the risk of leaving the job.

In the second model (resignation by the employee) the hazard ratio for sex variable matches the estimate from the first model. Hazard ratio for the second level of the remuneration variable has similar value to its counterpart in the first model. Third remuneration level turned 
out to be statistically insignificant. Employees with smallest earnings had 50\% lower hazard ratio compared to the same parameter in the first model. Factory staff was the only significant employee group in this model. Assembly line employees had 89.1\% lower risk of resigning from work compared to the top and middle management group. Workers with only primary education had $154.8 \%$ higher risk of voluntary turnover than those with a higher education. If we compare this figure with the corresponding estimate from the first model, we learn that the risk had almost doubled. Hazard estimates for age variable in both models are comparable.

Sex and education were statistically insignificant in the model for dismissals initiated by employer. The hazard estimates for remuneration variable were higher in all three groups compared to the first model. It is worth noting that the risk of dismissal for the employees in the lowest income group rose more than ten times. Therefore, employees with the remuneration lower than in the highest remuneration group experienced greater risk of dismissal compared to the employees belonging to the highest remuneration group. Hazard ratio for age variable is similar to the corresponding ratios in the first and second model.

The third model, in which the destination event of interest was defined as mutual agreement between employer and employee, all independent variables had at least one level which was statistically significant. Age and education variables had similar hazard ratios to the model that included all analysed event types. People in the lowest and second remuneration group had slightly higher risk of exit than those in the highest income group compared to the outcomes in the first model. Once again, the only statistically significant employee group consisted of factory workers. Employees who worked in the factory had by $88.2 \%$ greater risk of exit by mutual agreement than employees in the top and middle management group - the resulting figure is $7.5 \%$ higher than the corresponding one from the first model and almost matching the result from the model for work resignation by employee. The hazard rate for vocational education turned out to be marginally lower than the very same estimates in previous models. Moreover, no major differences between hazard estimate for age in this and previous models were observed.

The results of the last model are the closest to the estimates from the first model, in which no distinction was made about the event type. What is more, the estimates for sex and age in this model were the highest in all analysed models. However, the outcome of Wald test suggests that the null hypothesis assuming the equality of coefficients for sex variable between fourth and second model and between fourth and third model cannot be rejected. The results of test for age coefficients in analysed model and model for dismissals initiated by employer suggest that 
the null hypothesis should not be rejected. Whereas, the null hypotheses for the two remaining models were rejected.

Looking at the Tables 3 and 4, we can conclude that the coefficients differ across different event types. Taking into account the log-likelihood value, based on Chi-square statistic at 0.05 significance level with 39 degrees of freedom, the null hypothesis assuming that $\beta_{j}=\beta$ for all $j$ s, where $j=1,2, \ldots, 4$ ought to be rejected.

\section{Conclusions}

The results of competing risks model without covariates suggest that the job contract termination initiated by the employer is the least likely across all analysed job exits and periods. Furthermore, the job resignation by an employee is also very unlikely compared to the two remaining exit types and follows the very same trend like dismissals by the employer.

These results may suggest that the analysed company did not experience periods of increased turnover. Also, we may conclude that this enterprise possesses reliable recruiting process, because both employees and employer are not eager to terminate job contracts. This sort of analyses also carry an information about the company's condition - no periods of escalated dismissal have been identified. In addition, the company has stable employment level. Survival function decreases for job exit types other that those initiated by employer or employees are not intensified and usually take place after numerous months from the beginning of employment. Therefore, they exhibit the features of natural turnover process that should be observed in every company.

Estimation of competing risks models with covariates enabled us to examine the influence of selected determinants of turnover process. The Labour Law prohibits any employment discrimination based on sex, religion or race. The analysis of sex variable showed that this kind of discrimination is not present in the context of job terminations. Regardless of the event type, women have smaller risk of job exits compared to the male employees. These results differ largely from majority of studies that point to the worse women situation on the labour market (Drobnič, Frątczak, 2001). This might be explained by a relatively limited number of women in the overall company headcount and specific characteristics of the industry area.

Currently, in Poland and in other European countries we observe high unemployment rates among those who are just entering the labour market (Grzenda, 2012). Elderly workers (50+) share the very same difficult situation, labour participation rates in Poland for this group are 
among the lowest in entire Europe (Błędowski, 2013). In the analysed company, the risk of job contract termination is decreasing with age.

Remuneration scheme and salary level are key determinants affecting the length of the employment and risk of turnover. In Poland, remuneration plays a crucial role in the employee turnover and retention process and has necessary means to influence it (Pocztowski, 2009). From this research, we learned that the remuneration level differentiates the most noticeably the risk of job termination. Furthermore, the risk of exit is significantly different for each event type. The lowest remuneration group had definitely higher risk of leaving company compared to the employees in the highest group in the model for dismissals initiated by employer.

Constantly growing demand for information technologies and applications causes fierce competition between companies for best specialists on the market (Pocztowski, 2009). In this company, variable employee group does not differentiate evidently the risk of employee resignation from work regardless of the event type. We learn that low-skilled workers, who were considered as important production factor in the industrial era, nowadays do not play a significant role.

In a highly competitive world based on knowledge, employees with high qualifications and higher education have an edge over other workers on the labour market. According to other publications employees with a university degree have bigger chances of finding work (Grzenda, 2012). Therefore, those employees possess higher risk of terminating job contract compared to the workers with secondary and lower education. Described situation takes place in the analysed company.

The competing risks models enabled us to examine the influence of demographic and socioeconomic features of employees on employment duration. The scope of the analysis was limited by the data availability. Voluntary and involuntary turnover can be also influenced by other, mainly subjective employees' judgements concerning employment conditions. They can encompass relationships with other employees and bosses, promotion opportunities, availability of the trainings, the ability to cope with tasks an employee is responsible for, working hours and many other aspects. In order to incorporate these determinants one must resort to conducting surveys among employees who are leaving the company. Unfortunately, the collection of this kind of data for such a long period of time, as the one used in this study, is nearly impossible. 


\section{References}

Allison, P.D. (2010). Survival Analysis Using SAS: A Practical Guide. USA: SAS Institute.

Allison, P.D. (2010). Survival Analysis. In: G.R. Hancock, R.O. Mueller (eds.), Survival analysis in The Reviewer's Guide to Quantitative Methods in the Social Sciences (pp. 413-425). New York: Routledge.

Błędowski, P. (2013). Aktywność zawodowa osób w starszym wieku. In: M. Kiełkowska (ed.), Rynek pracy wobec zmian demograficznych. Zeszyty Demograficzne, 52-63.

Cascio, W.F. (2001). Kalkulacja kosztów zasobów ludzkich. Kraków: Oficyna Ekonomiczna.

Cox, D.R. (1972). Regression models and life tables (with discussion). Journal of the Royal Statistical Society, 34, 187-220.

Cox, D.R. (1975). Partial Likelihood. Biometrika, 62, 269-276.

Cox, D.R., Oakes, D. (1984). Analysis of Survival Data. Monographs and Statistics and Applied Probability. New York: Chapman \& Hall.

Cybulski, K. (2008). Przyczyny i konsekwencje wysokiej fluktuacji personelu sprzedażowego. Studia i Materiaty - Wydział Zarządzania UW, 1, 105-114.

Drobnič, S., Frątczak, E. (2001), Employment Patterns of Married Women in Poland, In: H.P. Blossfeld, S. Drobnič (eds.), Careers of Couples in Contemporary Societies (pp. 281-306). New York: Oxford University Press.

Gregory-Smith, I., Thompson, S., Wright, P.W. (2009). Fired or Retired? A Competing Risks Analysis of Chief Executive Turnover. The Economic Journal, 119, 463-481.

Grzenda, W. (2012). Badanie determinant pozostawania bez pracy osób młodych z wykorzystaniem semiparametrycznego modelu Coxa. Przeglad Statystyczny, I, 123-138.

Heckman, J.J., Honoré, B.E. (1989). The Identifiability of the Competing Risks Model. Biometrika, 76, 325-330.

Kalbfleisch, J.D., Prentice, R.L. (2012). The Statistical Analysis of Failure Time Data. Second Edition. USA: Wiley.

Klein, J.P. (2010). Competing risks. USA: Wiley.

Kleinbaum, D.G., Klein, M. (2012). Survival Analysis (3rd ed.). Springer.

Lunn, M., McNeil, D. (1995). Applying Cox regression to competing risks. Biometrics, 51 (2), 524-532.

Pintilie, M. (2006). Competing Risks: A Practical Perspective. New York: Jon Wiley \& Sons.

Pocztowski, A. (ed.), (2009). Procesy plynności i retencji zatrudnienia w organizacji, Kraków: Wydawnictwo Uniwersytetu Ekonomicznego w Krakowie. 
Prentice, R.L., Kalbfleisch, J.D., Peterson, Jr. A.V., Flournoy, N., Farewell, V.T., Breslow, N.E. (1978). The analysis of failure time in the presence of competing risks. Biometrics, $34,541-554$.

Sidor-Rządkowska, M. (2010). Zwolnienia pracowników a polityka personalna firmy. Warszawa: Wolters Kluwer.

Somers, M.J. (1996). Modelling employee withdrawal behaviour over time: A study of turnover using survival analysis. Journal of Occupational and Organizational Psychology, 69, 315-326.

Staw, B.M. (1980). The consequences of turnover. Journal of Occupational Behaviour, 1, 253273. 